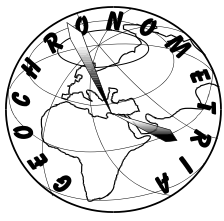

Conference Proceedings of the $4^{\text {th }}$ Asia Pacific Luminescence and Electron Spin Resonance Dating Conference Nov $23^{\text {rd }}-25^{\text {th }}, 2015$, Adelaide, Australia

Guest Editor: Lee Arnold

\title{
THE EFFECT OF TEST DOSE AND FIRST IR STIMULATION TEMPERATURE ON pOSt-IR IRSL MEASUREMENTS OF ROCK SLICES
}

\author{
JINFENG LIU ${ }^{1}$, ANDREW MURRAY ${ }^{2}$, REZA SOHBATI ${ }^{2,3}$ and MAYANK JAIN ${ }^{3}$ \\ ${ }^{1}$ State Key Laboratory of Earthquake Dynamics, Institute of Geology, China Earthquake Administration, China \\ ${ }^{2}$ Nordic Laboratory for Luminescence Dating, Department of Geoscience, Aarhus University, DTU Risø Campus, Denmark \\ ${ }^{3}$ Center for Nuclear Technologies, DTU Nutech, Technical University of Denmark, DTU Risø Campus, Denmark
}

Received 3 February 2016

Accepted 29 November 2016

\begin{abstract}
Optically stimulated luminescence (OSL) is increasingly applied to the dating of rock surfaces. There is at present no practical way of separating pure minerals (quartz and feldspar) from hard rocks for OSL measurement without losing the grain-size dependent dosimetric information and there is little information about the performance of the single-aliquot regeneration-dose (SAR) measurement protocol on the post-infrared infrared stimulated luminescence (pIRIR) signals from rock slices. The latter is investigated here. Our data indicate that there is a systematic increase in dose response curve saturation (or $D_{\mathrm{o}}$ ) with test dose size when the regeneration doses are first given in increasing order, and then decreasing order. This trend disappears if these orders are reversed. The reproducibility of dose response curves is dependent on the size of the test dose (poorer for small test dose). For rock slices given a saturation dose in the laboratory, it is observed that the sensitivity corrected pIRIR $_{290}$ signal lies close to saturation level of the dose response curve, for first IR stimulation at temperatures between 50 and $250^{\circ} \mathrm{C}$. However, the pIRIR 290 signal from naturally saturated slices lies close to the laboratory saturation levels only for higher first IR stimulation temperatures e.g. $200^{\circ} \mathrm{C}$ or $250^{\circ} \mathrm{C}$. Our data confirm earlier suggestions based on sand-grain measurements that, for older samples, accurate measurements close to saturation require that a higher first IR temperature is used.
\end{abstract}

Keywords: luminescence dating, rock surface, post-IR IRSL (pIRIR), SAR protocol, test dose correction, first IR stimulation temperature.

\section{INTRODUCTION}

Recently, optically stimulated luminescence (OSL) has been proposed as a geochronological tool applicable to rock surfaces (e.g. Vafiadou et al., 2004; Simms et al.,

Corresponding author: J. Liu

e-mail: liujf81@ies.ac.cn
2011; Liritzis, 2011; Sohbati et al., 2011, 2012, 2015; Chapot et al., 2012; Freiesleben et al., 2015). OSL dating techniques have been predominantly developed for quartz and feldspar as target minerals. Although the quartz luminescence signal is more stable than that of feldspar (Aitken, 1985), it is not always possible to find samples with a useful quartz sensitivity when dating solid rocks (Sohbati et al., 2011; Guralnik et al., 2015). In addition, it is difficult to separate pure mineral phases in igneous rock slices without losing grain-size dependent dosimet- 
ric information (Sohbati et al., 2011); however earlier studies have shown that the infrared stimulated luminescence (IRSL) signal in blue emission band from coarse grains is mainly associated with K-rich feldspar (e.g. Baril and Huntley, 2003; Sohbati et al., 2013). Unfortunately, the conventional IRSL signal suffers from anomalous or athermal fading (Wintle, 1973; Aitken, 1985; Spooner, 1994) and as a result has proved to be of limited value in dating. However, the feldspar signal derived from infrared stimulation at elevated temperature, measured after stimulation at about $50^{\circ} \mathrm{C}$ or higher temperature (the so-called post-IR IRSL or pIRIR; Thomsen et al., 2008; Buylaert et al., 2012; Li and Li, 2012a) seems to circumvent this problem and offers considerable potential for the dating of older material. Over the last few years, the pIRIR signal from feldspar has been increasingly applied to the dating of different types of sedimentary samples (e.g. Buylaert et al., 2009; Li and Li, 2011; Thiel et al., 2011), but there is little information on the performance of the single-aliquot regeneration-dose (SAR) measurement protocol (Murray and Wintle, 2000) on the pIRIR signal from rock slices.
The size of the test dose (e.g. Qin and Zhou, 2012; Buylaert et al., 2012; Yi et al., 2016) and the stimulation temperature (e.g. Thomsen et al., 2008; $\mathrm{Li}$ and Li, 2012b) are important parameters in pIRIR dating. In this study, we investigate the effect of test-dose size and first stimulation temperature on the pIRIR $_{290}$ signals from rock slices, especially from those close to saturation. This is undertaken using both natural and laboratory saturated samples.

\section{SAMPLE AND MEASUREMENT INSTRUMENT}

Aliquots were taken from a glacial granite gneissic boulder (MUST88) sampled in July 2013 from the Pamir plateau, Western China (Fig. 1) previously dated to $\sim 80$ ka by Seong et al. (2009) using ${ }^{10}$ Be. Several blocks of $\sim 4 \times 4 \times 7 \mathrm{~cm}$ were cut from the surface of the boulder using a petrol-driven cut-off saw equipped with a diamond blade. Sample preparation and luminescence signal measurements were carried out at the Institute of Geology (China Earthquake Administration, China) and at the Nordic Laboratory for Luminescence Dating, Aarhus
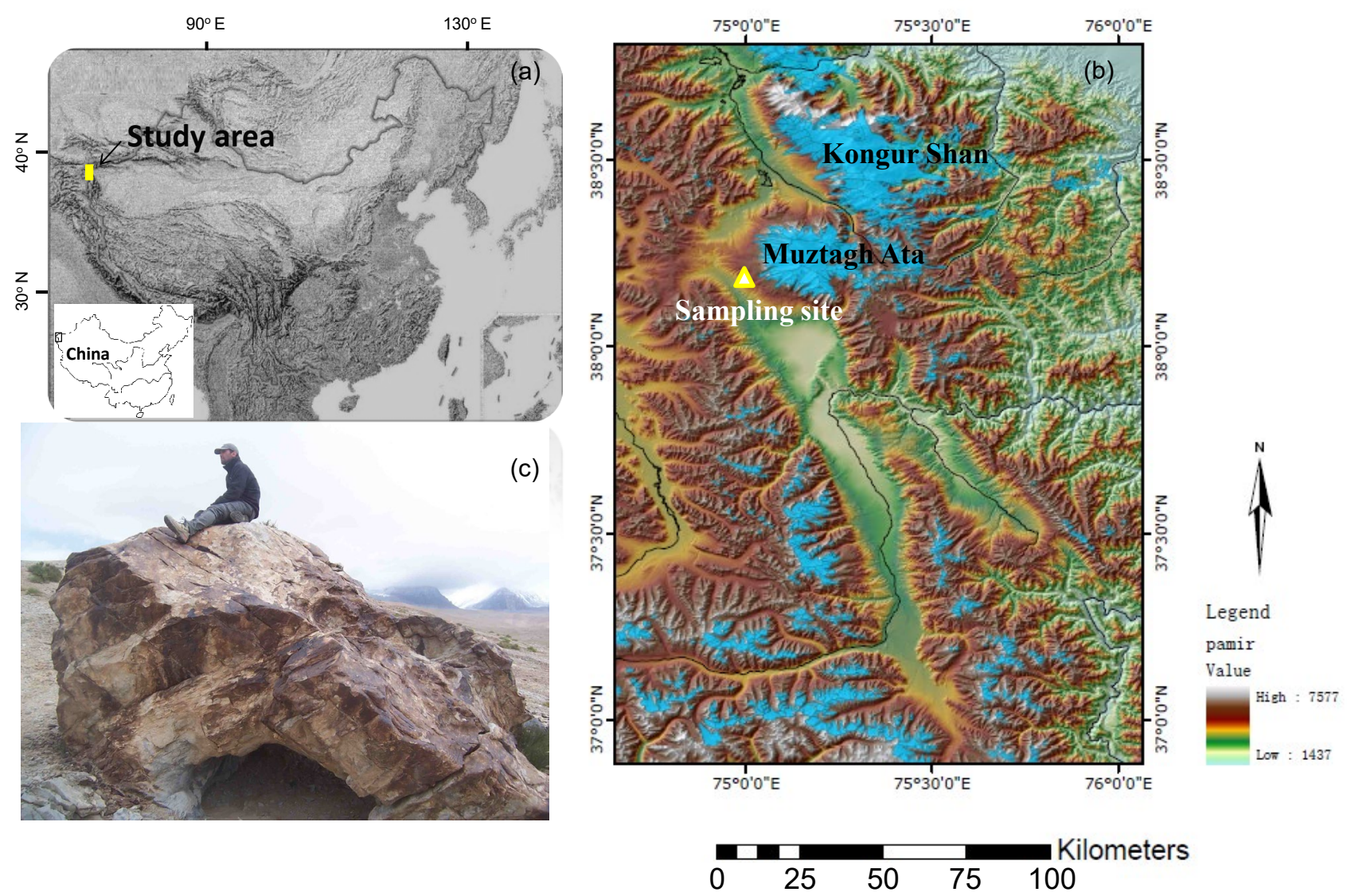

Fig. 1. (a) Study area located at the western part of China, Pamir Plateau. (b) Samples were taken from the SW side of the Muztagh Ata massif. This fig was modified after the Fig. $1 \mathrm{~A}$ in Owen et al., (2012). (c) Photo of the glacial gneissic boulder (MUST 88) from which the sample was taken (Seong et al., 2009). 
University, Denmark and Center for Nuclear Technologies (DTU Nutech), Technical University of Denmark. Under subdued red-orange light, cores $\sim 10 \mathrm{~mm}$ in diameter and up to $40 \mathrm{~mm}$ long were drilled from these blocks using a water-cooled diamond core drill; these cores were then cut into $1.2 \mathrm{~mm}$ thick slices using a water-cooled low-speed saw equipped with a $0.3 \mathrm{~mm}$ thick diamond wafer blade, giving a net slice spacing of $1.5 \mathrm{~mm}$. The surface slices were treated with $10 \% \mathrm{HF}$ for $30-40 \mathrm{~min}$ and $10 \% \mathrm{HCl}$ for $20 \mathrm{~min}$ to remove any weathering products. No treatment was undertaken on inner slices (Sohbati et al., 2011).

Rock slices were put in a carousel directly and measured on a Risø TL/OSL reader Model DA-20, using infrared stimulation $\left(870 \mathrm{~nm}, \sim 130 \mathrm{~mW} / \mathrm{cm}^{2}\right)$ and photon detection through a Schott BG 39/Corning 7-59 filter combination ( 2 and $4 \mathrm{~mm}$, respectively). Beta irradiation used a calibrated ${ }^{90} \mathrm{Sr} /{ }^{90} \mathrm{Y}$ source mounted on the reader (Bøtter-Jensen et al., 2010).

\section{METHODS AND RESULTS}

\section{Luminescence characteristics of $\mathbf{I R}_{\mathbf{5 0}}$ and pIRIR $_{\mathbf{2 9 0}}$}

The measurement protocol shown in Table 1A (modified after Thiel et al., 2011) was used to measure the $\mathrm{IR}_{50}$ and pIRIR $_{290}$ signals. For calculations employing a net signal, the initial $2 \mathrm{~s}$ of the signal minus a background evaluated from the last $10 \mathrm{~s}$ of the $200 \mathrm{~s}$ stimulation was used. Fig. 2a shows the natural $\mathrm{IR}_{50}$ and $\mathrm{pIRIR}_{290}$ decay curves for one slice from a depth of $\sim 30 \mathrm{~mm}$ into the rock surface from a single core. Fig. $2 b$ shows the sensitivitycorrected natural $\mathrm{IR}_{50}$ and pIRIR $\mathrm{R}_{290}$ signal $\left(\mathrm{L}_{\mathrm{n}} / \mathrm{T}_{\mathrm{n}}\right)$ of slices plotted against depth, normalized to the average $L_{n} / T_{n}$ at depths $>15 \mathrm{~mm}$. Negligible signal was detected up to a depth of $\sim 8 \mathrm{~mm}$ for $\mathrm{IR}_{50}$ and $\sim 4 \mathrm{~mm}$ for pIRIR 290 into the rock, because of zeroing of the signal near the surface. Based on the fitting of the simple rock-surface-exposure model (Equation 5.5 from Sohbati et al. 2011; the solid curves), the $\mathrm{IR}_{50}$ and pIRIR 290 signals are in field saturation at depths $>12 \mathrm{~mm}$ and $>10 \mathrm{~mm}$, respectively. The values at these depths are scattered, presumably because of variability in the $D_{\mathrm{o}}$ across the slices. However, the individual pIRIR $290 \mathrm{~L}_{\mathrm{n}} / \mathrm{T}_{\mathrm{n}}$ values from these depths lie very close to the saturation level in their respective laboratory dose response curve (Fig. 2a inset), while the natural $\mathrm{IR}_{50}$ signal (solid symbols) is $\sim 50 \%$ of laboratory saturation.

\section{Inheritance in the test dose response}

At high doses, even a small residual remaining after the measurement of $L_{x}$ signals could significantly affect the signals from small test doses and so have an effect on the final $D_{\mathrm{e}}$ estimate (e.g. Qin and Zhou, 2012; Nian et al., 2012; Fu et al., 2015). We first investigated the size of any inherited signal arising due to thermal transfer and/or insufficient zeroing during measurement of the $L_{x}$ signals, using the sequence outlined in Table 1B. After measurement of the natural signal from various slices and thermo-optically bleaching (IRSL for $200 \mathrm{~s}$ at $325^{\circ} \mathrm{C}$ ) any remaining signal, a high regeneration (4400 Gy) dose was given to each slice, which were then measured according to Table 1B. Fig. 3 shows the ratio of the inherited IR and pIRIR signals (steps $1-5,1-6$, Table 1B) to the corresponding initial signals (steps $1-3,1-4)$ plotted against preheat temperature. For the $\mathrm{IR}_{50}$ signal this ratio is consistently $\sim 0.2 \%$ except at the highest two preheat temperatures $\left(>360^{\circ} \mathrm{C}\right)$ where this ratio begins to increase to a maximum of $\sim 0.5 \%$ at $400^{\circ} \mathrm{C}$. In contrast, the inherited pIRIR signal decreases with temperature from $\sim 2 \%$ at $260^{\circ} \mathrm{C}$ to $\sim 0.6 \%$ at $360^{\circ} \mathrm{C}$. Assuming that the dose re-

Table 1. The post-IR IRSL SAR protocols used in this study

\begin{tabular}{|c|c|c|c|}
\hline Step & $\bar{A}$ & B & $\mathrm{C}^{3}$ \\
\hline $1-1$ & Natural or Regeneration dose & Dose (4400 Gy) & $\begin{array}{l}\text { Natural, Natural+2688 Gy, bleached+2688 Gy or Re- } \\
\text { generation dose }\end{array}$ \\
\hline $1-2$ & Preheat at $320^{\circ} \mathrm{C}$ for $100 \mathrm{~s}$ & Preheat at $\mathrm{T}^{\circ} \mathrm{C}$ for $100 \mathrm{~s}^{1}$ & Preheat at $320^{\circ} \mathrm{C}$ for $100 \mathrm{~s}$ \\
\hline $1-3$ & IR at $50^{\circ} \mathrm{C}$ for $200 \mathrm{~s}\left(\mathrm{~L}_{x, 50}\right)$ & IR at $50^{\circ} \mathrm{C}$ for $200 \mathrm{~s}\left(\mathrm{~L}_{\text {sat }, 50}\right)$ & $\mathrm{IR}$ at $\mathrm{T}^{\circ} \mathrm{C}$ for $200 \mathrm{~s}^{2}$ \\
\hline $1-4$ & IR at $290^{\circ} \mathrm{C}$ for $200 \mathrm{~s}\left(\mathrm{~L}_{x, 290)}\right.$ & IR at $(\mathrm{T}-30)^{\circ} \mathrm{C}$ for $200 \mathrm{~s}\left(\mathrm{~L}_{\text {sat }} \mathrm{T}-30\right)$ & IR at $290^{\circ} \mathrm{C}$ for $200 \mathrm{~s}$ (Ln or Lsat) \\
\hline $1-5$ & & $\mathrm{IR}$ at $50^{\circ} \mathrm{C}$ for $200 \mathrm{~s}(\text { Linherited }, 50)^{\prime}$ & \\
\hline$\overline{1-6}$ & & IR at $(\mathrm{T}-30)^{\circ} \mathrm{C}$ for $200 \mathrm{~s}($ Linherited, $\mathrm{T}-30)$ & \\
\hline$\overline{2-1}$ & Test dose & & Test dose \\
\hline $2-2$ & Preheat at $320^{\circ} \mathrm{C}$ for $100 \mathrm{~s}$ & & Preheat at $320^{\circ} \mathrm{C}$ for $100 \mathrm{~s}$ \\
\hline $2-3$ & IR at $50^{\circ} \mathrm{C}$ for $200 \mathrm{~s}\left(\mathrm{~T}_{\mathrm{x}, 50}\right)$ & & $\mathrm{IR}$ at $\mathrm{T}^{\circ} \mathrm{C}$ for $200 \mathrm{~s}$ \\
\hline $2-4$ & IR at $290^{\circ} \mathrm{C}$ for $200 \mathrm{~s}\left(\mathrm{~T}_{\mathrm{x}, 290)}\right.$ & & IR at $290^{\circ} \mathrm{C}$ for $200 \mathrm{~s}\left(\mathrm{~T}_{\mathrm{n}}\right.$ or $\left.\mathrm{T}_{\text {sat }}\right)$ \\
\hline$\overline{3-1}$ & IR at $325^{\circ} \mathrm{C}$ for $200 \mathrm{~s}$ (Thermo-optical wash) & & IR at $325^{\circ} \mathrm{C}$ for $200 \mathrm{~s}$ (Thermo-optical wash) \\
\hline
\end{tabular}

${ }^{1} T$ ranges from 260 to $400^{\circ} \mathrm{C}$ in steps of $20^{\circ} \mathrm{C}$.

${ }^{2} \mathrm{~T}$ is 50,200 and $250^{\circ} \mathrm{C}$

$3 / n$ experiment $C, L_{n}$ is the signal resulting from the natural dose, the natural+2688 Gy or bleached+2688 Gy, as appropriate. $T_{n}$ is the corresponding test dose signal 

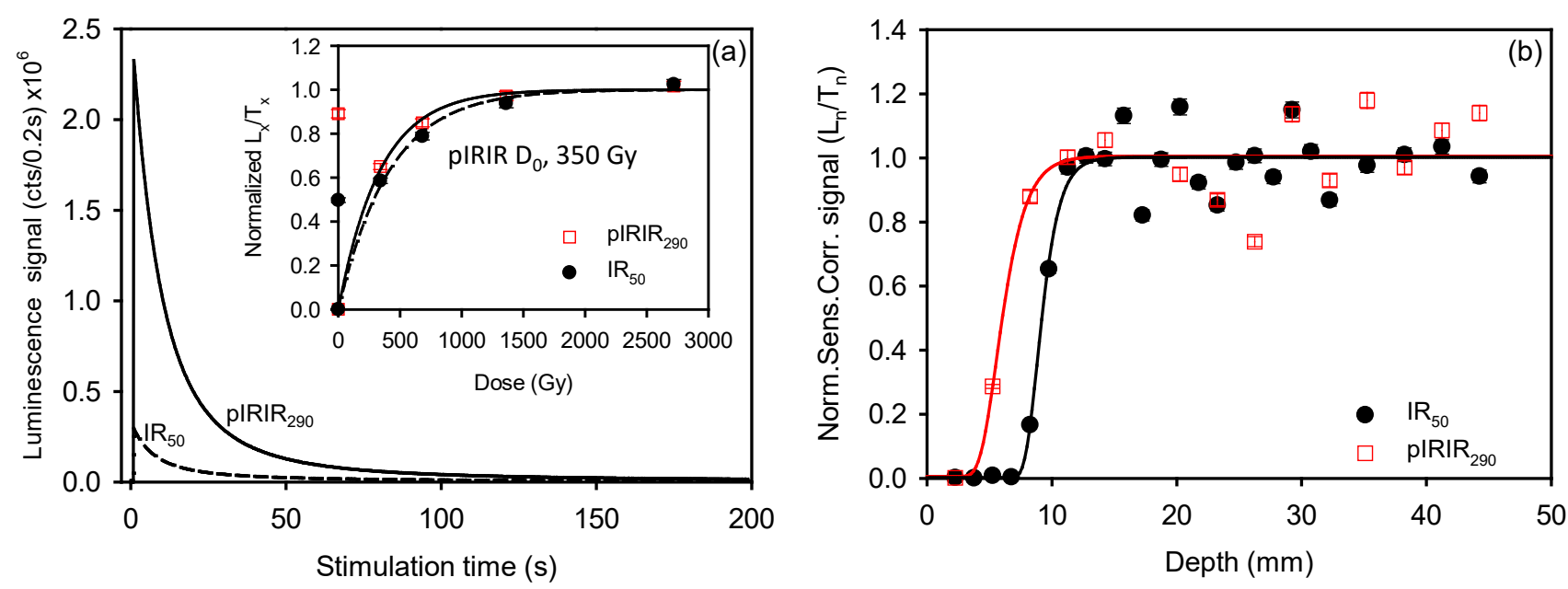

Fig. 2. (a) Typical decay curves and (inset) dose response curves of $I R_{50}$ (dashed line) and pIRIR 290 (solid line) signals. (b) The variation of the $I R_{50}$ and pIRIR 290 "residual signals" with depth into the rock surface.

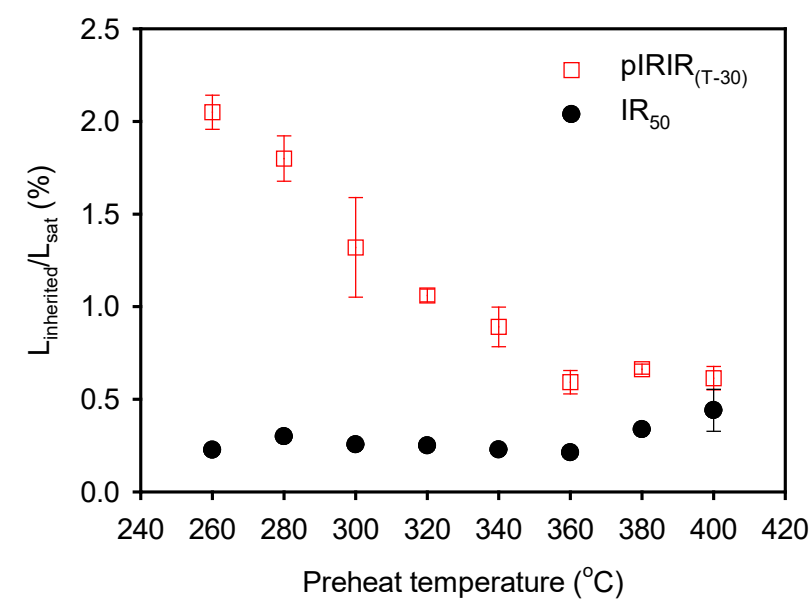

Fig. 3. The ratio of the "residual signal" (steps 1-5, 1-6, Table 1B) to the initial signal (steps 1-3, 1-4) at different preheat and stimulation temperatures. Three slices were measured at each temperature. The error bars represent one standard error.

sponse curve follows an exponential growth, an inherited signal of $2 \%$ corresponds to an inherited dose of $\sim 7 \mathrm{~Gy}$ (using the $D_{\mathrm{o}}$ of 350 Gy from Fig. 2 inset). This implies that for samples recording a large dose resulting in signals at or close to saturation, any test dose should be significantly larger than 7 Gy. This is discussed further below (next section).

\section{Measuring rock slices in saturation: effect of test dose size and the order of regeneration dose}

Six sets of experiments were undertaken to test the influence of test dose on the pIRIR 290 dose response curves and the accuracy of the measured equivalent doses; these involve changing the order in which the regeneration doses were given (Tso and Li, 1994; Timar-Gabor and
Wintle, 2013), and the size of the test dose. Three saturated slices from the inner part of rock core (depth $>15 \mathrm{~mm}$ ) were used for each set of experiment (i.e. 18 naturally saturated slices in total). The $L_{x} / T_{x}$ results are shown in Fig. 4, normalized to the saturation value of their corresponding fitted dose response curve (single saturating exponential function). The insets show the $L_{x}$ data alone without test dose normalization. In Fig. 4a, 4c, 4e, after the measurement of the natural signal, the regeneration doses were (1) given in increasing order, then (2) repeated, but in decreasing order, and finally in step (3) the highest dose ( $2700 \mathrm{~Gy})$ was repeated again. In the second group of experiments (Fig. $\mathbf{4 b}, \mathbf{4 d}, \mathbf{4 f}$ ), the regeneration doses were (1) first given in decreasing order and then (2) in increasing order before (3) the highest dose was re-measured. In Fig. $4 a$ and $\mathbf{4 b}$, the test dose was only $4 \mathrm{~Gy}$. These experiments were repeated with a larger test dose of 53 Gy to give Fig. $4 \mathbf{c}$ and $\mathbf{4 d}$, and a much larger test dose of 595 Gy to give Fig. 4 e and $\mathbf{4 f}$.

Comparison of the shapes of the dose response curves suggests that in the first group of experiments (regeneration doses first given in increasing order) the value of $D_{\mathrm{o}}$ increases with the size of the test dose (Fig. 4a, 4c, 4e). However, there is no such correlation in the second group where the regeneration doses were initially given in a decreasing order; here $D_{\mathrm{o}}$ seems to be independent of the test dose size (Fig. $\mathbf{4 b}, \mathbf{4 d}, \mathbf{4 f}$ ). For clarity all the dose response curves are summarized in Figs. 5a and 5b. Although the potential natural variation in the $D_{\mathrm{o}}$ values of individual slices as implied from the luminescence-depth profile (see Fig. 2b) may preclude any conclusive interpretation of these data, this observation is nevertheless noteworthy because each dose response curve is an average of three curves measured from three different naturally saturated slices.

A further comparison of the sensitivity-corrected dose response curves constructed by giving doses in increasing 

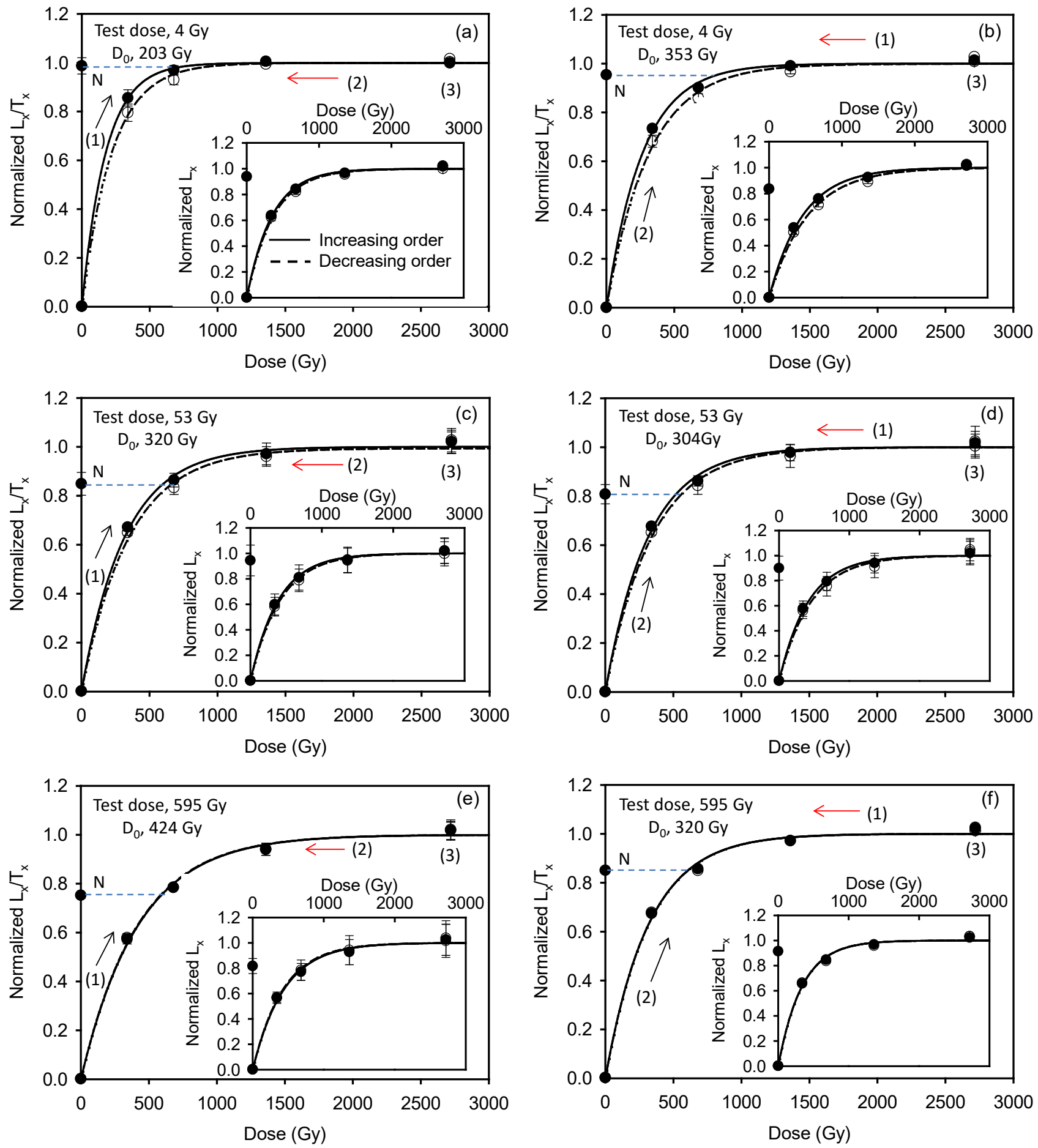

Fig. 4. Laboratory dose response curves for different test doses, where the regeneration doses are given in increasing or decreasing order. For (a) and (b) the test dose is $4 \mathrm{~Gy}$, (c) and (d) $\sim 53 \mathrm{~Gy}$, and (e) and (f) $~ 595 \mathrm{~Gy}$. The solid and dashed lines represent doses given in increasing and decreasing order, respectively. The numbers (1), (2) and (3) show the order in which the regeneration doses were given. Three slices were measured at each point. The insets show the dose responses of the sensitivity uncorrected signal $\left(L_{x}\right)$. All data were normalized to the saturation value of their corresponding fitted dose-response curve. The $D_{0}$ values corresponding to the solid $L_{x} / T_{x}$ curves, based on a single saturating exponential fit, are presented in the individual figures. 

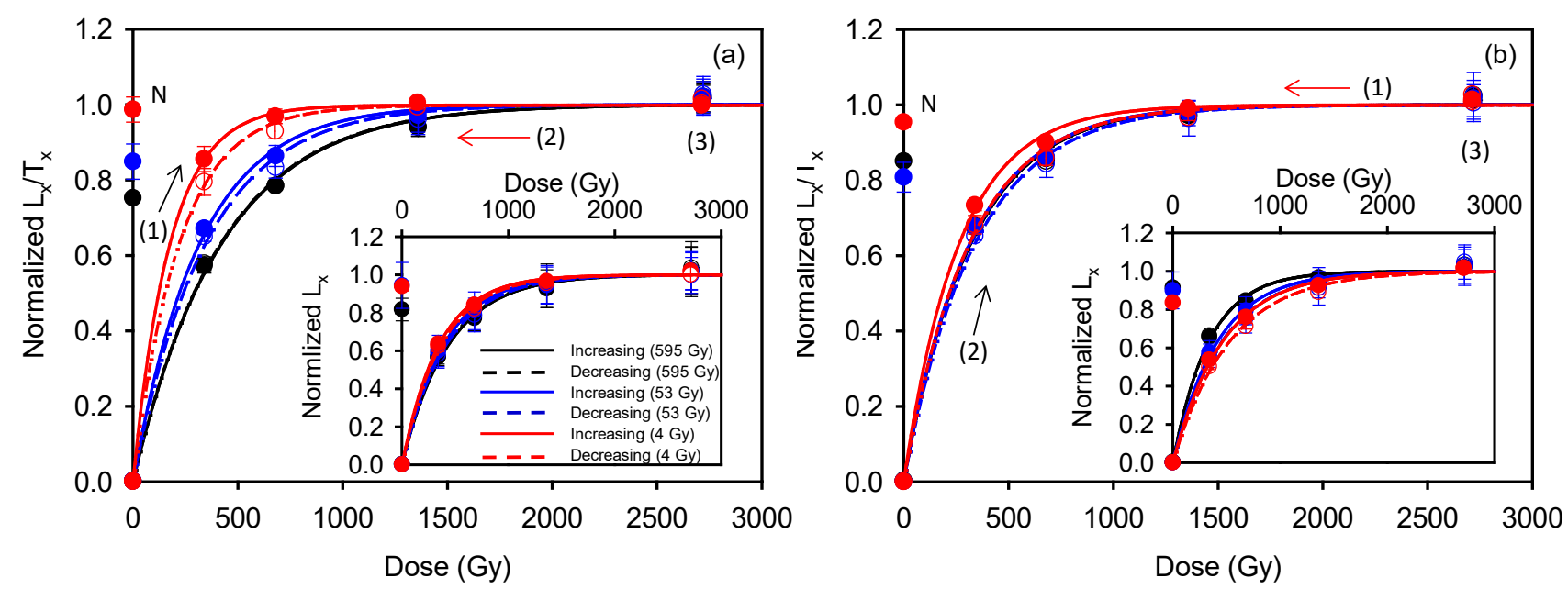

Fig. 5. a) Summary of data in Fig. 4a, $4 c$ and 4e. b) Summary of data in Fig. $4 b, 4 d$ and $4 f$.

and decreasing order (in the same experiment) indicates that their reproducibility improves as the test dose increases (Fig. 4a-f; note the discrepancies between the solid and dashed curves). The reproducibility is poorer when a small test dose (4 Gy) is used to measure dose response curves up to saturation, and independent of the order in which regeneration doses are given (Fig. 4a and 4b). However, it becomes increasingly better when the test dose size is increased (Fig. 4c, 4d, 4e, 4f). In Fig. 4e, 4f, with the largest test dose (595 Gy), the solid and dashed curves overlap.

Although the natural signal appears to be closer to saturation in the dose response curves that have not been corrected for sensitivity change (Fig. 4 insets), this is likely to be an artefact of sensitivity change; Fig. 6 shows that the test-dose response drops by $\sim 10 \%$ between the natural and the first regeneration SAR cycle. When the
$\mathrm{L}_{\mathrm{x}} / \mathrm{T}_{\mathrm{x}}$ data are examined (Fig. 4), the natural signal lies $1 \%$ (Fig. 4a) and 5\% (Fig. 4b) below laboratory saturation for the 4 Gy test dose, 15 (Fig. 4c) and 19\% (Fig. 4d) below for the 53 Gy test dose, and 25 (Fig. 4e) and $15 \%$ (Fig. 4f) below for the 595 Gy test dose. The apparent saturation (or close to saturation) of the natural signal for the 4 Gy test dose is possibly a reflection of the inheritance effect discussed above.

\section{Effect of first IR stimulation temperature}

In this experiment, three groups of slices were measured, where the first IR stimulation temperature was $50^{\circ} \mathrm{C}, 200^{\circ} \mathrm{C}$ or $250^{\circ} \mathrm{C}$ (Fig. 7, Table $1 \mathrm{C}$ ). The purpose of this experiment is to see which prior treatment gives the most reliable dose estimate. Group (1) consisted of naturally saturated slices from the inner part of the rock
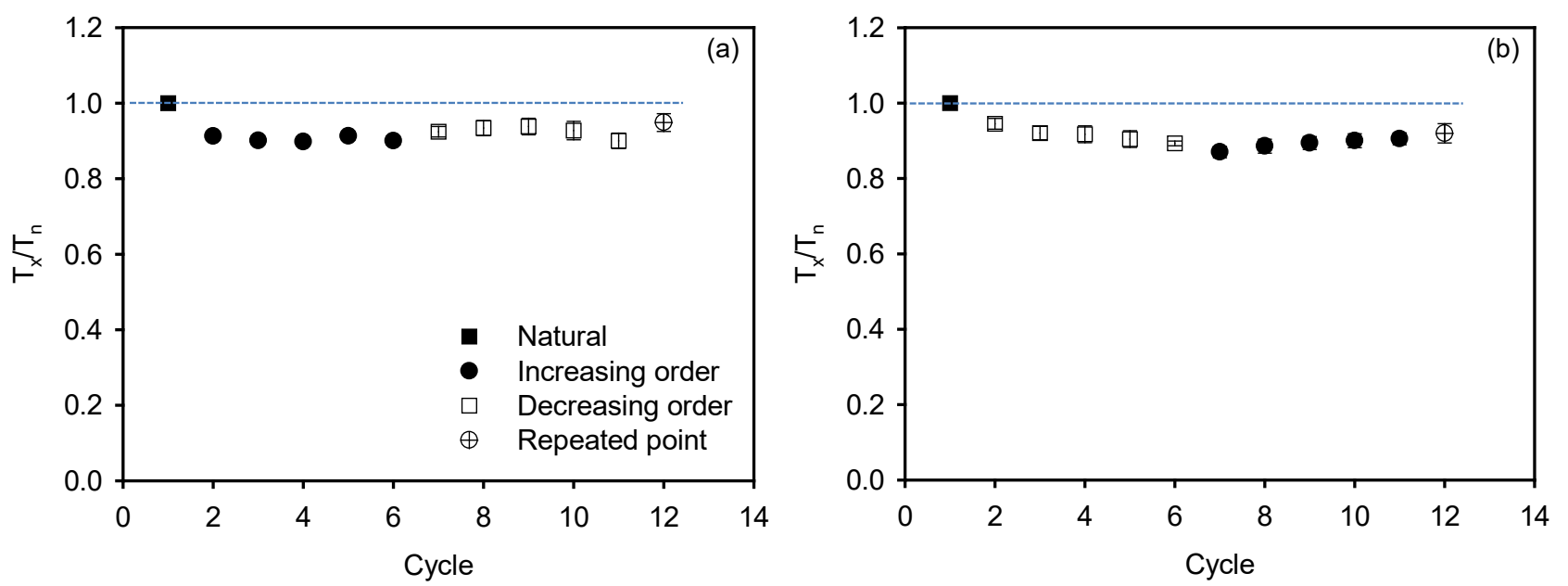

Fig. 6. Sensitivity change monitored by a large test dose (595 Gy). (a) Increasing regeneration doses followed by decreasing doses. (b) Decreasing regeneration doses followed by increasing doses. Three slices were used at each point. 
(depth $>15 \mathrm{~mm}$ ). Group (2) contained naturally saturated slices from the inner part of the rock to which a high dose of 2688 Gy had been added. Group (3) contained naturally bleached slices from the surface of the rock to which a high dose of 2688 Gy was added. All these samples were then measured and " $\mathrm{L}_{\mathrm{n}} / \mathrm{T}_{\mathrm{n}}$ " (first cycle measurements resulting from natural, natural $+2688 \mathrm{~Gy}$, or bleached +2688 Gy, as appropriate) were derived. Subsequently, a regenerated dose cycle with 2688 Gy was undertaken using all these slices; this cycle gave an estimate of the laboratory saturation signal $\mathrm{L}_{\mathrm{sat}}$ and its corresponding test dose response $T_{\text {sat }}$. The ratios of the " $L_{n}$ " to $L_{\text {sat }}$ and " $L_{n} / T_{n}$ " to $L_{s a t} / T_{\text {sat }}$ are shown as a function of first stimulation temperatures in Fig.7, for two sizes of test dose, 53 Gy (Fig. 7a, 7c) and 595 Gy (Fig. 7b, 7d). These data are similar to those from a dose recovery test except that we are considering the reproducibility of light levels (luminescence intensities) rather than doses.
Consider first Fig. 7a, 7b where the uncorrected absolute light level ratios $\left(\mathrm{L}_{\mathrm{n}} / \mathrm{L}_{\text {sat }}\right)$ are presented. In both figures, the natural signals $\left(\mathrm{L}_{\mathrm{n}}\right)$ are within $10 \%$ of the regenerated $L_{\text {sat }}$ signals, suggesting that the natural light level is indistinguishable from the regenerated saturated light level, as was also indicated in Fig. 4 insets. However the ratios of $\mathrm{L}_{\mathrm{n}+2688} / \mathrm{L}_{\text {sat }}$ and $\mathrm{L}_{\text {bleached }+2688} / \mathrm{L}_{\text {sat }}$ are all $>1$ (unfilled diamond and unfilled square symbols in Fig. 7a, $7 \mathrm{~b}$ ); this confirms that the apparent saturation of the natural signal is an artefact of the change in sensitivity during the measurement of the first SAR cycle (see Fig. 6 and discussion above). Fig. 7c, 7d present the sensitivity corrected ratios $\left(\mathrm{L}_{\mathrm{x}} / \mathrm{T}_{\mathrm{x}}\right)$. Here most of the $\mathrm{L}_{\mathrm{n}+2688} / \mathrm{T}_{\mathrm{n}+2688}$ and $\mathrm{L}_{\text {bleached }+2688} / \mathrm{T}_{\text {bleached }+2688}$ signals are consistent with the corrected regenerated signals $\left(\mathrm{L}_{\mathrm{sat}} / \mathrm{T}_{\text {sat }}\right)$ at $2 \sigma$, indicating a good recovery ratio for samples saturated in the laboratory. However, for the naturally saturated slices (group 1), the signal is $<0.9$ for first stimulation tempera-

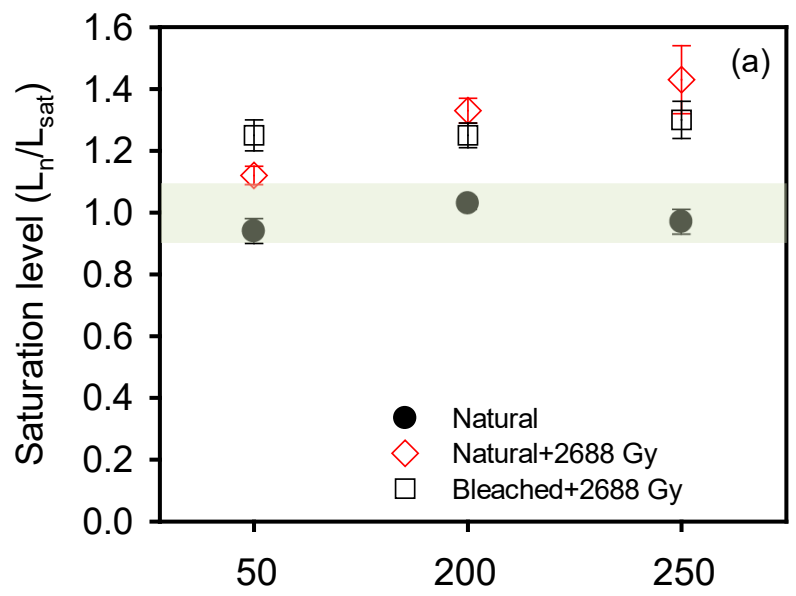

First stimulation temperature $\left({ }^{\circ} \mathrm{C}\right)$

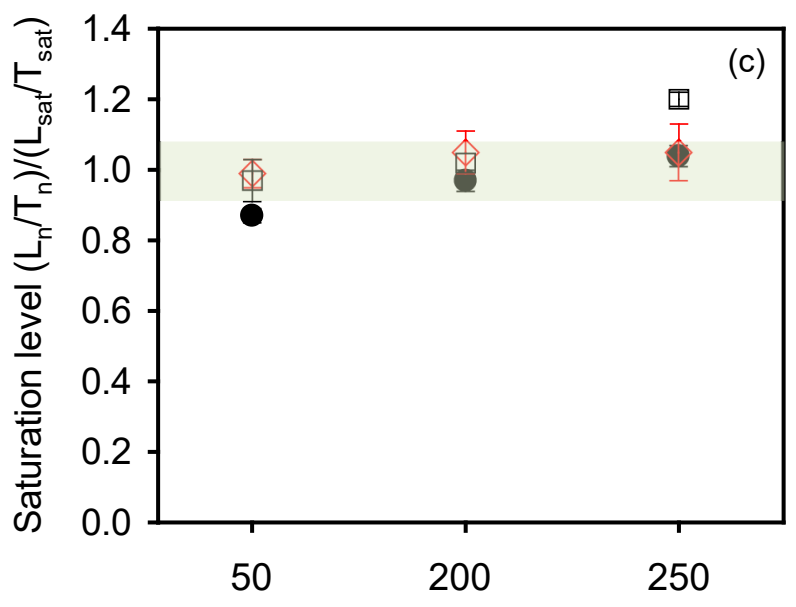

First stimulation temperature $\left({ }^{\circ} \mathrm{C}\right)$

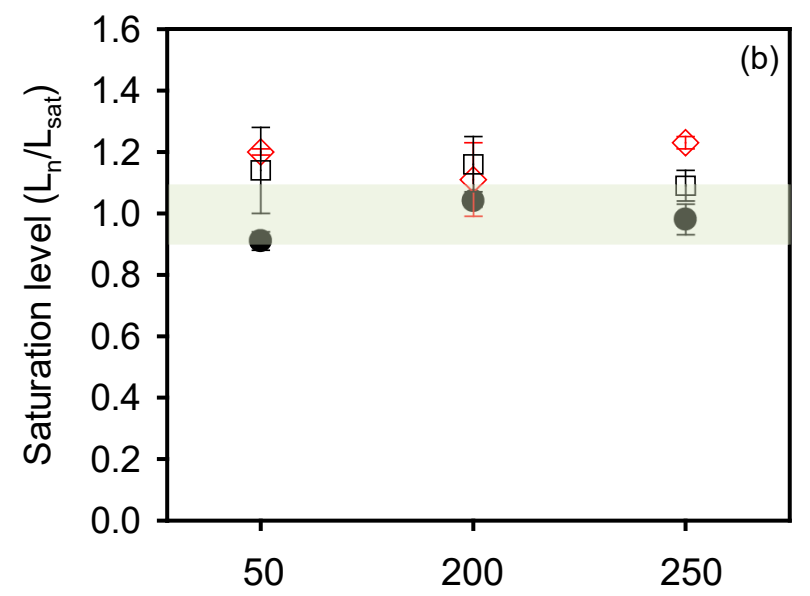

First stimulation temperature $\left({ }^{\circ} \mathrm{C}\right)$

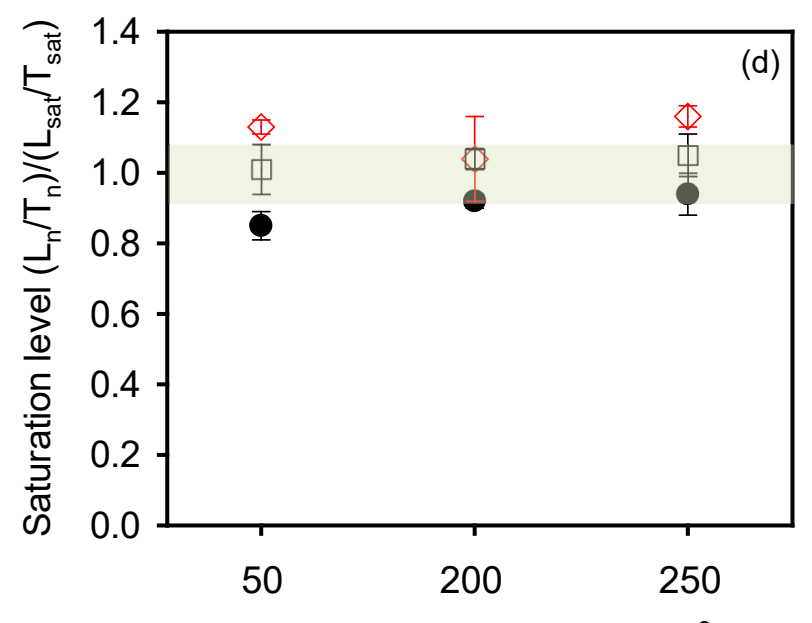

First stimulation temperature $\left({ }^{\circ} \mathrm{C}\right)$

Fig. 7. Effect of first stimulation temperature on the degree of saturation. Test doses in (a) and (c) are 53 Gy and in (b) and (d) $\sim 595 \mathrm{~Gy}$. The shadowed area covers $10 \%$ deviation from unity (i.e. 0.9 to 1.1). Three slices were measured at each temperature. The error bars represent one standard error. 
ture at $50^{\circ} \mathrm{C}$. This effect is independent of test-dose size and could possibly be because we are sampling a less stable signal with a lower prior IR stimulation temperature. However, there is also a tendency for an increase in the levels of laboratory dosed $\mathrm{L}_{\mathrm{n}+2688} / \mathrm{T}_{\mathrm{n}+2688}$ and $\mathrm{L}_{\text {bleached }+2688} / \mathrm{T}_{\text {bleached }+2688}$ with a prior IR stimulation temperature, and in fact some data lie above unity; thus, the increase cannot be solely attributed to signal stability. Our data suggest that an apparent increase in the ratio with IR stimulation temperature could be a combination of both sensitivity change and increased stability. It may also be that the results obtained using a first stimulation temperature of $200^{\circ} \mathrm{C}$ are closer to unity that those obtained using $250^{\circ} \mathrm{C}$, although at this stage we do not wish to place too much confidence in this conclusion.

\section{DISCUSSION AND CONCLUSION}

We find that the reproducibility of the sensitivitycorrected dose response curve is poorer when a small test dose (4 Gy) is used to measure dose response curves up to saturation; however the small test dose gives the best agreement between the natural signal (expected to be in saturation) and the dose response curve. This result may be attributed to the inheritance effect, which can translate into a dose as high as 7 Gy (section 3 - Inheritance in the test dose response) and thus be a source of significant contamination in the test dose pIRIR 290 signal. We are unable to detect a significant effect of inheritance in the comparison of the large 595 Gy and 53 Gy test doses in the subsequent experiments (reproducibility of laboratory dose-response curves, Fig. 4, or first to second cycle saturation light level ratios, Fig. 7). This is presumably because even the 53 Gy test dose was $>7$ times larger than any potential inheritance. Fig. $4 \mathbf{c}-\mathbf{f}$ indicates that laboratory measurements of dose-response curves are reproducible and, when the test doses are much larger than the inheritance dose (7 Gy) in any given experiment, the resulting dose-response curves are independent of the order in which regeneration doses are given. Perhaps surprisingly this is equally true of absolute light levels (Fig. 4 insets) and $\mathrm{L}_{\mathrm{x}} / \mathrm{T}_{\mathrm{x}}$ ratios. Although it appears that the absolute light levels $\left(\mathrm{L}_{\mathrm{x}}\right)$ give natural signals closer to saturation, we argue that this is an artefact of a significant change in sensitivity especially in the first SAR cycle (Fig. 6). This argument is supported by the comparison of the non-normalized and test-dose normalized ratios of the "natural" to laboratory saturation levels (Fig. 7). Although the non-normalized ratios are close to unity for the natural signal, these ratios are up to 1.4 (Fig. 7a) for the samples which were saturated in the laboratory $\left(\mathrm{L}_{\mathrm{n}+2688} / \mathrm{L}_{\text {sat }}\right.$ and $\left.\mathrm{L}_{\text {bleached }+2688} / \mathrm{L}_{\text {sat }}\right)$ before the first measurement cycle (test dose), clearly indicating a significant change in sensitivity. This is in contrast to the ratios of the test-dose normalized data which are generally much closer to unity, although there remains some underestimate for a first stimulation temperature of $50^{\circ} \mathrm{C}$. It is interesting to note that $\mathrm{Li}$ and $\mathrm{Li}(2012 \mathrm{a})$ and $\mathrm{Yi}$ et al. (2016) have both observed an underestimation in $D_{\text {e }}$ plateau for a first stimulation temperature of $50^{\circ} \mathrm{C}$, although several authors (e.g. Buylaert et al., 2012, 2015; Yi et al., 2015) have shown that natural doses up to 650 Gy are independent of first stimulation temperature. It may be that the underestimates derived from the test-dose corrected natural saturation light levels (Fig. 7 for a first stimulation temperature of $50^{\circ} \mathrm{C}$ ) only become significant for large palaeodoses.

Our data indicate that there is a systematic increase in dose response curve saturation (or $D_{\mathrm{o}}$ ) with test dose size when the regeneration doses are first given in increasing order, and then decreasing order (Fig. 5a). This trend disappears if these orders are reversed (Fig. 5b). We do not at present understand this effect.

In conclusion, for our samples, it appears that when measuring large doses, (i) the saturation of the dose response curve changes as a function of the test dose if the regeneration doses are delivered in an increasing order, but this effect is not so important if the regeneration doses are delivered in the decreasing order, (ii) the size of the test dose should be significantly larger than the apparent dose corresponding to any carryover from the previous measurement, and (iii) it may be better to use a first stimulation temperature of at least $200^{\circ} \mathrm{C}$ for samples close to saturation, regardless of the size of the test dose.

\section{ACKNOWLEDGMENTS}

This work was financially supported by the State Key Laboratory of Earthquake Dynamics (project no.: LED2013A09), the National Natural Science Foundation of China (project no.: 41472161). RS would like to thank Carlsberg Foundation for financial support (Grant no. 2012_01_0838) during this project. JL thanks Luo Ming for assistance in the field and Zhang Huiping for providing Fig. 1b. Chen Jie and Wang Xulong are acknowledged for useful discussions.

\section{REFERENCES}

Aitken MJ, 1985. Thermoluminescence dating. Academic Press, London: 274-281pp.

Baril MR and Huntley DJ, 2003. Infrared stimulated luminescence and phosphorescence spectra of irradiated feldspars. Journal of Physics: Condensed Matter 15: 8029-8048, DOI 10.1088/09538984/15/46/018.

Buylaert J-P, Murray AS, Thomsen KJ and Jain M, 2009. Testing the potential of an elevated temperature IRSL signal from K-feldspar. Radiation Measurements 44(5-6): 560-565, DOI 10.1016/j.radmeas.2009.02.007.

Buylaert J-P, Jain M, Murray AS, Thomsen KJ, Thiel C and Sohbati R, 2012. A robust feldspar luminescence dating method for Middle and Late Pleistocene sediments. Boreas 41: 435-451, DOI 10.1111/j.1502-3885.2012.00248.x.

Buylaert J-P, Yeo E-Y, Thiel C, Yi SW, Stevens T, Thompson W, Frechen M, Murray AS and Lu HY, 2015. A detailed post-IR IRSL chronology for the last interglacial soil at the Jingbian loess site (northern China). Quternary Geochronology 30(Part B): 194199, DOI 10.1016/j.quageo.2015.02.022. 
Bøtter-Jensen L, Thomsen KJ and Jain M, 2010. Review of optically stimulated luminescence (OSL) instrumental developments for retrospective dosimetry. Radiation Measurements 45(3-6): 253-257, DOI 10.1016/j.radmeas.2009.11.030.

Chapot MS, Sohbati R, Murray AS, Pederson JL and Rittenour TM, 2012. Constraining the age of rock art by dating a rock-fall event using single-grain and surface dating luminescence techniques. Quaternary Geochronology 13: 18-25, DOI 10.1016/j.quageo.2012.08.005.

Freiesleben T, Sohbati R, Murray AS, Jain M, al Khasawneh S, Hvidt S and Jakobsen B, 2015. Mathematical model quantifies multiple daylight exposure and burial events for rock surfaces using luminescence dating. Radiation Measurements 81: 16-22, DOI 10.1016/j.radmeas.2015.02.004

Fu X, Li SH and Li B, 2015. Optical dating of aeolian and fluvial sediments in north Tian Shan range, China: Luminescence characteristics and methodological aspects. Quaternary Geochronology 30 (B): 161-167, DOI 10.1016/j.quageo.2015.03.001.

Guralnik B, Ankjærgaard C, Jain M, Murray AS, Müller A, Walle M, Lowick SE, Preusser F, Rhodes EJ, Wu T-S, Mathew G and Herman F, 2015. OSL-thermochronometry using bedrock quartz: A note of caution. Quaternary Geochronology 25: 37-48, DOI 10.1016/j.quageo.2014.09.001.

Li B and Li SH, 2011. Luminescence dating of K-feldspar from sediments: a protocol without anomalous fading correction. Quaternary Geochronology 6(5): 468-479, DOI 10.1016/j.quageo.2011.05.001.

Li B and Li SH, 2012a. A reply to the comments by Thomsen et al. on "Luminescence dating of K-feldspar from sediments: A protocol without anomalous fading correction". Quaternary Geochronology 8: 49-51, DOI 10.1016/j.quageo.2011.10.001.

Li B and Li SH, 2012b. Luminescence dating of Chinese loess beyond $130 \mathrm{ka}$ using the non-fading signal from K-feldspar. Quaternary Geochronology 10: 24-31, DOI 10.1016/j.quageo.2011.12.005.

Liritzis I, 2011. Surface dating by luminescence: An overview. Geochronometria 38(3): 292-302, DOI 10.2478/s13386-011-0032-7.

Murray AS and Wintle AG, 2000. Luminescence dating of quartz using an improved single-aliquot regenerative-dose protocol. Radiation Measurements 32(1): 57-73, DOI 10.1016/S1350-4487(99)00253-X.

Nian XM, Bailey RM and Zhou LP, 2012. Investigation of the post-IR IRSL protocol applied to single K-feldspar grains from fluvial sediment. Radiation Measurements 47(9): 703-709, DOI 10.1016/j.radmeas.2012.03.024

Owen LA, Chen J, Hedrick KA, Caffee MW, Robinson AC, Schoenbohm L M, Yuan Z, Li W, Imrecke DB and Liu JF, 2012. Quaternary glaciation of the Tashkurgan Valley, Southeast Pamir. Quaternary Science Reviews 47: 56-72, DOI 10.1016/j.quascirev.2012.04.027.

Qin JT and Zhou LP, 2012. Effects of thermally transferred signals in the post-IR IRSL SAR protocol. Radiation Measurements 47(9): 710-715, DOI 10.1016/j.radmeas.2011.12.011.

Seong YB, Owen LA, Yi CL and Finkel RC, 2009. Quaternary glaciation of Muztag Ata and Kongur Shan: Evidence for glacier response to rapid climate changes throughout the Late Glacial and
Holocene in westernmost Tibet. GSA Bulletin 121(3-4): 348-365, DOI 10.1130/B26339.1.

Simms AR, DeWitt R, Kouremenos P and Drewry AM, 2011. A new approach to reconstructing sea levels in Antarctica using optically stimulated luminescence of cobble surfaces. Quaternary Geochronology 6(1): 50-60, DOI 10.1016/j.quageo.2010.06.004.

Sohbati R, Murray AS, Chapot MS, Jain M and Pederson JL, 2012. Optically stimulated luminescence (OSL) as a chronometer for surface exposure dating. Journal of Geophysical Research-Solid Earth 117, B09202, DOI 10.1029/2012JB009383.

Sohbati R, Murray A S, Porat N, Jain M, and Avner U, 2015. Age of a prehistoric "Rodedian" cult site constrained by sediment and rock surface luminescence dating techniques. Quaternary Geochronology 30, 90-99, DOI 10.1016/j.quageo.2015.09.002.

Sohbati R, Murray AS, Jain M, Buylaert J-P and Thomsen KJ, 2011. Investigating the resetting of OSL signals in rock surfaces. Geochronometria 38(3): 249-258, DOI 10.2478/s13386-011-0029-2.

Sohbati R, Murray AS, Jain M, Thomsen K, Hong S-C, Yi K and Choi $\mathrm{J}-\mathrm{H}, 2013$. Na-rich feldspar as a luminescence dosimeter in infrared stimulated luminescence (IRSL) dating. Radiation Measurements 51-52: 67-82, DOI 10.1016/j.radmeas.2012.12.011.

Spooner NA, 1994. The anomalous fading of infrared-stimulated luminescence from feldspars. Radiation Measurements 23(2-3): 625632, DOI 10.1016/1350-4487(94)90111-2.

Thiel C, Buylaert J-P, Murray AS, Terhorst B, Hofer I, Tsukamoto S and Frechen M, 2011. Luminescence dating of the Stratzing loess profile (Austria) - Testing the potential of anelevated temperature post-IR IRSL protocol. Quaternary International 234(1-2): 23-31, DOI 10.1016/j.quaint.2010.05.018.

Thomsen KJ, Murray AS, Jain M and Bøtter-Jensen L, 2008. Laboratory fading rates of various luminescence signals from feldspar-rich sediment extracts. Radiation Measurements 43(9-10): 1474-1486, DOI 10.1016/j.radmeas.2008.06002.

Timar-Gabor A and Wintle AG, 2013. On nature and laboratory generated dose response curves for quartz of different grain sizes from Romanian loess. Quaternary Geochronology 18: 34-40, DOI 10.1016/j.quageo.2013.08.001.

Tso M-YW and Li SH, 1994. Equivalent dose estimation for pottery by single disc regeneration method. Radiation Measurements 23(23): 451-454, DOI 10.1016/1350-4487(94)90078-7.

Vafiadou A, Murray AS and Liritzis I, 2007. Optically stimulated luminescence (OSL) dating investigations of rock and underlying soil from three case studies. Journal of Archaeological Science 34: 1659-1669, DOI 10.1016/j.jas.2006.12.004.

Wintle AG, 1973. Anomalous fading of Thermoluminescence in Mineral Samples. Nature 245: 143-144, DOI 10.1038/245143a0.

Yi SW, Buylaert J-P, Murray AS, Thiel C, Zeng L and Lu HY, 2015. High resolution OSL and post-IR IRSL dating of the last interglacial-glacial cycle at the Sanbahuo loess site (northeastern China). Quaternary Geochronology 30 (Part B): 200-206, DOI 10.1016/j.quageo.2015.02.013.

Yi SW, Buylaert J-P, Murray AS, Lu HY, Thiel C and Zen L, 2016. A detailed post-IR IRSL dating study of the Niuyangzigou loess site in Northeastern China. Boreas 45(4): 644-657, DOI 10.1111 /bor. 12185 . 